\title{
THE IMPACT OF URBAN TRANSPORTATION ON AIR POLLUTION AND THE ROLE OF SUBWAY INITS CONTROL (TEHRAN, BEIJING, BARCELONA)
}

\author{
B. Khoshmanesh ${ }^{*}, \mathrm{~S}$. Nasr \\ Parand Branch, Islamic Azad University, Parand, Iran
}

Published online: 16 July 2016

\begin{abstract}
Many scholars believe that air pollution can be defined when it is mixed with technical indicators. Therefore, in his legal dictionary, Garner has defined air pollution as any material and harmful energy that directly or indirectly emit in the air in such as a way that harm the environment, welfare, or public health. Air pollution has both natural and synthetic origin. In the meantime, transport is one of the causes of pollution that is in artificial emissions group and has a major contribution to air pollution.Urban rail transportation is considered as an efficient factor in reducing transport-related pollution, and thusin addition to its ability in rapid and massive transportation, subway can play an important role in sustainable urban development. In this article, we have tried to examine the role of transportation in urban air pollution as well as the subway role in reducing these emissions, and subways in Tehran, Beijing, and Barcelona have been investigated and the outstanding role of subway is identified because of the high volume of human transportation and reducing traffic in the city.
\end{abstract}

Key words: transportation, air pollution, subways, traffic

Author Correspondence, e-mail: behnoush84@yahoo.com

doi: http://dx.doi.org/10.4314/jfas.v8i2s.106 


\section{INTRODUCTION}

Air is a colorless, odorless gas and a mixture of elements such as nitrogen, oxygen, carbon dioxide, argon, neon, helium, krypton, xenon,water vapor, and some ammonia gas. Air, like other environmental resources, has limited capacity and does not have the tolerance of dumping different toxic waste to the extent that human imposeson it today.

Air pollution is one of the most important environmental issues in urban life today, especially in developing countries, so that this problem has always been the focus of attention for urban and environmental authorities (Karimi, 2013). Air pollution is one of the aspects of environmental pollution that increase heart and breathing,disease vision, bring about eye irritation, and damage to plants, animals, and objects.At global level, it leads to global warming, loss of stratospheric ozone, acid rain and so on (Sabouhi and Mousavi, 2014).According to the World Health Organization estimate, exposure to air pollution leads to premature death of 865,000 people annually, primarily due to cardiac effects (James, Bereitschaft, 2011). With the rapid growth of urbanization in recent decades, urban transport has become one of the major urban problems. Increase of use of private vehicles in major cities increases traffic and subsequently increased travel time and pollution levels (HadiZonooz et al., 2011).Urban transport is one of the important factors of life and economic growth of the city and is considered as the most effective sector of transport. According to the World Bank report in developing countries, 15 and 25 percent of the budget, 8 to 16 percent of household income and more than $33 \%$ of capital investment in urban infrastructure is in the transport sector (Sabouhi and Mousavi, 2014).In Iran as one of the developing countries, particularly in subwaypolises, the increasing number of vehicles and the need to transport intensify the problem of air pollution.Concerning the environmental consequences of air pollution, to achieve environmental goals and clarify issues related to it for planners, preparation of environmental impact studies formulated in traffic management and road design have been taken into consideration and the purpose is to develop the demand for environmentally friendly and coordinated transportation with the help of this (Safarpour et al., 2015). The best means of public transport is urban rail transit or subway. Subwayis the most efficient urban mass transit system, and one of its most important benefits is its routes being separatefrom other urban routes. Thus, traffic ofpassengers of the subway does not interfere with urban traffic and in fact, subway eases the burden of city streets and takes toits underground.Due to the high volume of passengers transported by subway, it is the base of urban transport systems 
in big cities, and other transportation systems such as buses and taxis are used to supplement the subway. In the past years, creating subway lines in cities around the world has gained momentum. These days, in many cities of the world,no matter by what means the citizens start their journey in the city, they use subway for one path at least.

In Iran also, the development of subway is the best arena to serve the people in the field of urban transport. It is considered as a symbol of development and any operationdone for its construction and operation is an indicator of development. In addition, if really see the construction and operation of the subway as a process, it can be considered an indicator of progress in the development of the country (Montazeri, Dervishi, 2012).

\section{Research Methodology}

This article is prepared by review method.

\section{Sources of air pollution due to transport}

Pollution from transport due to arbitrarily expansion of cities is important. Pollution from transport or vehicles as a result of incomplete combustion of fossil fuels or vehicles engine wear, and other factors include $\mathrm{CO}, \mathrm{CO}_{2}, \mathrm{NO}_{\mathrm{x}}, \mathrm{SO}_{\mathrm{x}}$, particulates, noise, and so on (Arianof, et al., 2014).

\section{Problems of urban transport}

Urban transport sector activities cause external costs such as traffic, crossing routes, use of parking, and the cost of land allocation to activities related to the transport sector, estimation of irrevocable costs of accidents, environmental pollution cost anddelay in travel (OstadiJafari et al., 2012).Perhaps one of the reasons for this inefficiency is change in the transportation of people in recent years. In the past, people used to travel on bicycles, walking, trams, and buses because few of them had a car, but today, due to the higher people's purchasing power, lifestyle changes, the growth of cities, and the need to travel long distances, number of trips by personal vehicles has strongly increased (Pourashka et al., 2014).

\section{Green transport}

Green transport (sustainable) is the transport, which supports environmental sustainability by supporting the global climate, ecosystems, public health and natural resources and the other two poles of economic stability, especially economic pole (fair, efficient, and accessible transportation for everyone and supporting sustainable competitive economy through the development of safe area, balancing, and creating jobs),and social pole (meeting basic needs 
assessment and development of individuals, institutions, and society in a secure manner and in accordance with human health and ecosystems and supporting the reduction of poverty and creating intergenerational equity) (Aghayi et al., 2015).

One of the ways to sustainable urban development is reducing reliance on cars, and using public transport like subway can be very helpful in this area (ShahiriParsa et al., 2010).

\section{Subway}

In-city rail transportation is as an important part of urban basic facilities in the public transport system. By observing the urban development in all countries, rail freight transport, due to its advantages including high capacity, high speed, safety, high reliability, lower costs, and comfort, is as an essential tool in urban transport in developed countries and regions (Khaki, et al., 2012).

\subsection{The concept of efficiency of Subway}

Subway is a high-speed rail shipping method that all or part of it has been built underground,and through one or more specified path, all of which have fixed and accessible stations from the ground level, it provides the possibility of providing passenger transportation in the city (Nazariu et al, 2014).

\subsection{Subway benefits}

- Reduced gas consumption

- Reducing the cost of accidents and spare parts and so on

- Reduction of traffic

-Reduced waste of time

-Reduced air pollutants

- Reduced noise

-Reduced visual pollution

(Hassan Ghajar, Lotfi, 2011)

\section{Checking air pollution and subways in Tehran, Beijing and Barcelona}

\subsection{Tehran}

Tehran's irregular growth in recent decades and the lack of a systematic planning for urban development and design of streets and houses, location of industries and factories, mountains, and wind direction have caused severe pollution problems particularly at the time of temperature inversion (Gilandeh et al., 2014).Devotion of the most important spaces on the ground in Tehran to transportation and high mounted traffic volumeshave increased energy consumption and air 
pollution. Pollution from the transportation sector, due to rapid and uncontrolled urbanization,is as important as industrial pollution.

One could say that, reducing travel times and distances of movements within the city, the possibility topurify contamination of the air, and thus reduction in carbon monoxide, oxides of nitrogen, unburned hydrocarbons and suspended particles, change in the type of fuel due to the positive impact on fuel reducing air pollution in Tehranare ofthe benefits of development of underground transport (Bemaninan, Pourjafar., 2012).

According to the report byCommunications Management and International Affairs of Tehran Subway Operation, Tehran Subway officially started its work from March 7, 1999 with the opening and operation of high-speed Tehran - Karaj train. Now, after 14 years with four active lines has broken the record of daily transportation of more than two and a half million trips, the subway has started with the following general purposes:

1) The ability to travel within the city and the connection of suburbs withcenter of Tehran with good speed

2) Accurate and secure traffic with the highest possible technology

3) Attention to environmental issues by reducing the volume of pollutant transport network

4) Creation and spread a culture of discipline with respect to the value of the time in the daily lives of citizens

5) Creating a calm and comfortable social atmosphere

6) Optimization of urban transport

7) Saving Fuel

8) Reducing accidents

9) Saving time

10) Reducing the cost of treatment and cleaning of air pollution

11) Saving the cost of spare parts and vehicles depreciation

12) Subwaya step in the development of sustainable cities

Thus, this volume of trip shows Tehran subway large role in urban transportation and somehow involvement of all age and sex groups etc. (Nazari, et al., 2014).

\subsection{Beijing}

The rapid economic growth and urbanization have dramatically changed urban transportation in China. Reliance on motorized transport vehicles has caused some problems such as air pollution. 
China's capital Beijing has become one of the most car-dependent cities, from 2005 to 2010, the total number of motor vehicles has grown from 2580000 to 4800000 , and the number of private vehicles has been growing at around 1340000 to 3570000 .From 2000 to 2010 , the share of car in trips has increased from 23.2 percent to 34.2 percent (Sun, Zheng, Wang, 2014). Great public transport systems, promoting the transfer of people by them, reduction of transportation time, and even increase in the efficiency are of incentives for the use of public transport including the subway. In comparison with other public transportation, such as taxis and buses, subways has the features of high speed and capacity, timely service and special routes. In mid-2011, the average number of daily commuters in Beijing Subway was about seven million people and by the end of 2012, it reached more than nine million.

In Beijing, there is a plan called cleanup method in the subway that by measuring the exact time for each passenger examines different routes,and by taking into account the walking time in the subway, waiting for the train obtains the effective time of transmission by the subway and exit time. Based on this method, one can identify the time required to reach any destination, which is in itself has a significant impact on encouraging people, by knowing the exact time of arrival to use the subway(Leng, Zeng, Xiong, Weifeng, Wan, 2013).

\subsection{Barcelona}

In Barcelona, $40 \%$ reduction of long journeys by car and replacing it by public transport and bicycle had reduced 127 cases of diabetes, 44 cases of cardiovascular disease, 30 dementia, 11 cases of breast cancer, and 3 cases of colon cancer per years (Rueda,Nazelle, Teixido, Nieuwnhuijsen,2013).Barcelona subway system consists of eight lines at different depths with different sizes of tunnels. This transport system with high capacity to carry passengers throughout the day is suitable alternative for surface traffic. Subway system in Barcelona is one of Europe's oldest underground transport systems, with a total of $102.6 \mathrm{~km}$ route covered and 140 train station. Barcelona Subway has attracted about 50\% of the urban traffic and transports 1.25 million passengers during the week(Martins, moreno, Minguillon, Amato, De Miguel, Capdevila, Querol, 2015).

\section{DISCUSSION AND CONCLUSION}

According to the above-mentioned issues, air pollution causes problems both for humans and animals and plants, among which heart, breathing diseases, decreased vision, eye irritation, 
premature death and damage to plants, animals and objects and global warming can be noted. In the meantime, pollution from transportation by motor vehicles has an important role in air pollution in the city. Subway with its own special features can be used as an alternative to use less of motor vehicles, especially personal vehicles in trips within the city and even intercity ones.Subway expansion is very effective in reducing air pollution and therefore urban traffic. Like what was mentioned in the text, the existence of a system by which one can estimate the time it takes to get from the station to the destination (such as Beijing subway) as well as extending subway lines to most parts of the city, one can discuss subway to as a viable alternative to private cars in the urban trips. By spreading Subway, Barcelona has managed to allocate around $50 \%$ of the subway section to urban transport. Extending subway lines and facilities needed, and providing the necessary information, one may further replace car shipping, (by personal cars) with subway, and this issue in Tehran will help to develop sustainable transport.

\section{REFERENCES}

- Karimi, 2013.Air pollution and its effects on the environment, the National Conference of Environmental Research, 9 November

- Sabouhi and Mousavi, 2014.Studying the effects of air pollution caused by urban transport and ways to reduce it, the first international conference on the environment Safari, Sheikh Azzami, Hosseini, 2015. Weights of Sehri emissions of air pollutants by the standard method of air pollution Tier2 Corinair- case study in Sari, the fourth International Conference on Transportation and Traffic Engineering

- Montazeri, Dervishi, 2012.Air pollution and subway role in reducing its effects, Twelfth International Conference on Transportation and Traffic Engineering

- MolaeiKhajeh, GholipourAghdamYamchi, 2012.Air pollution, the first national conference on environmental protection and planning, 13 March

- Mousavian, 2012. The effects on the environment and public health urban transport network, the first national conference on environmental protection and planning, 13 March

- Ariyanof, Saei, Abbas Alizadeh, 2014. Tehran air pollution and emissions of cars at the first national conference on environmental health, health and environmental sustainability, September 11 
- OstadiJafari, Taherinejad, HaidarMeyabadi, 2012.The influencing factors and economic indicators on sustainable urban transport, the Eleventh International Conference on Engineering of freight traffic.

- Aghayi, Hadipour, Rahmani, 2015. Offering effective environmental factors and indicators of sustainable transportation in the city (Case Study: Qom), the International Conference on Transportation and Traffic Engineering.

- ShahiriParsa, Badiei, 2012.Future studies public transport in sustainable urban development, Twelfth International Conference on Transportation and Traffic Engineering.

- HadiZonooz, Zherraynejad, KhodaPanah.Outer consequences of transport by private car in Tehran, Journal of Quantitative Economics (former economic studies), Volume 8, Issue 2, Summer 2011, pp. 51-77.

- Khaki, JafariHaqiqatpour, Haj Ali, 2012.Assessing the role of inter-city rail transport system in order to promote economic development and reduce air pollution and provide guidelines for its development in Iran, the National Conference of transport infrastructure, 13 and 14 February

- Nazari, Moinifard, Omidi, 2014. Tehran urban subway transit system evaluation using factor analysis approach to strategic, sustainable development of the first National Conference on Geography and Planning, architecture and urbanism

- Pourashka, Ramezanian, NabiZadeh.Assessing the sustainability of urban transport systems (Case study: Rasht), Journal of Urban Economics and Management, Issue VIII, Autumn2014.

- Hassan Ghajar, Lotfi, 2011.Examining the role of sustainable development subway polis of Tehran Subway, National Conference of Civil Engineering, Urban Development and Energy Management, February

- Gilandeh, Taherpour, Akbari, 2014. Air pollution and its impact on creative cities Tehran Case Study, the second national conference on applied research in geography and tourism

- Bemanian, Pour Jafar.2012.The underground space development, transportation influencing energy efficiency and reduce air pollution in cities Case Study: Tehran, Elaine national conference on environmental protection and planning, 13 March. 
- Debbage.,2011 ,BEREITSCHAFT, BRADLEY JAMES FRANK, Ph.D. Urban Form and Air Quality in, U.S. Subwaypolitan and Megapolitan Areas.

- Sun,zheng,wang,2014, Restrictingdrivingforbettertrafficandclearerskies:Diditwork in Beijing?, Transport Policy

- Leng, Zeng, Xiong, Weifeng,Wan,2013, Probability tree based passenger flow prediction and its

- Application to the Beijing subway system, Front. Comput. Sci., 2013, 7(2): 195-203

- Rueda,Nazelle, Teixido, Nieuwnhuijsen,2013, Health impact assessment of increasing public transport and cycling use in Barcelona: Amorbidity and burden of disease approach, Preventive Medicine

- Martins,moreno,Minguillon,Amato, De Miguel,Capdevila,Querol,2015, Exposure to airborne particulate matter in the subway system, Science of the Total Environment 511 (2015) 711-722

How to cite this article:

Khoshmanesh B, Nasr S. The impact of urban transportation on air pollution and the role of subway inits control (tehran, beijing, barcelona). J. Fundam. Appl. Sci., 2016, 8(2S), 1700-1708. 